\title{
Effects of adenoviral vector expressing hIGF-1 on apoptosis in nucleus pulposus cells in vitro
}

\author{
CHANG-CHUN ZHANG ${ }^{1,2}$, GUO-PENG CUI ${ }^{1,2}$, JIAN-GUO HU ${ }^{2}$, YU-ZHOU XIAO ${ }^{1,2}$, \\ XIN-SHE ZHOU ${ }^{1,2}$, CHEN SHAO ${ }^{1,2}$, QINGHUA LIN ${ }^{1,2}$ and JIAN-SHENG ZHOU ${ }^{1,2}$ \\ ${ }^{1}$ Department of Orthopedics and ${ }^{2}$ Anhui Key Laboratory of Tissue Transplantation, \\ The First Affiliated Hospital of Bengbu Medical College, Bengbu, Anhui 233004, P.R. China
}

Received August 22, 2013; Accepted November 28, 2013

DOI: $10.3892 /$ ijmm.2013.1586

\begin{abstract}
The excessive apoptosis of cells of the nucleus pulposus may plays an important role in intervertebral disc (IVD) degeneration. It has been shown that the pro-inflammatory cytokine tumour necrosis factor (TNF)- $\alpha$ can induce disc cell apoptosis. Insulin-like growth factor (IGF)-1 can promote nucleus pulposus cell proliferation; however, whether or not IGF-1 inhibits TNF- $\alpha$-induced apoptosis in the nucleus pulposus has not yet been elucidated. In this study, our objective was to create a potentially therapeutic viral vector, which could be used to achieve the enforced expression of IGF-1 in rabbit nucleus pulposus cells. Furthermore, we investigated the ability of IGF-1 to reverse TNF- $\alpha$-induced apoptosis in cells of the nucleus pulposus. Isolated nucleus pulposus cells were cultured to a confluent monolayer, digested with collagenase II and purified using trypsin and differential adhesion methods. Nucleus pulposus cells were positively identified using type II collagen immunohistochemistry. Following transfection with adenoviral vectors engineered to overexpress recombinant human IGF-1 (Ad-hIGF-1) or TNF- $\alpha$, the cells were observed under a light microscope. Terminal deoxynucleotidyl transferase (TdT)-mediated dUTP-biotin nick end-labeling (TUNEL) and flow cytometry (FCM) were used to assess the rate of apoptosis. The Ad-hIGF-1 viral vector was effectively transduced into the nucleus pulposus cells and increased IGF-1 expression as confirmed by RT-PCR and western blot analysis. In the TNF- $\alpha$ treated group, a large number of apoptotic cells was observed that exhibited morphological changes associated with this form of cell death. Minimal apoptosis was observed in the Ad-hIGF1-treated group and the control group showed no obvious signs of apoptosis. TUNEL assay revealed that the rate of apoptosis in the Ad-hIGF-1 group was significantly reduced compared with the TNF- $\alpha$-treated group $(\mathrm{P}<0.01)$. This result was confirmed using
\end{abstract}

Correspondence to: Professor Jian-Sheng Zhou, Department of Orthopedics, The First Affiliated Hospital of Bengbu Medical College, 287 Chang Huai Road, Bengbu, Anhui 233004, P.R. China E-mail: bbmcjszhou@163.com

Key words: adenoviral vector, insulin-like growth factor-1, nucleus pulposus cells, apoptosis
FCM. The rate of apoptosis was also significantly increased in the TNF- $\alpha$-exposed cells compared with the control group $(\mathrm{P}<0.01)$. Our findings strongly suggest that the adenoviral vector expressing hIGF-1 can successfully infect nucleus pulposus cells in vitro and effectively enhance the expression of IGF-1. In addition, IGF-1 reversed the TNF- $\alpha$-induced apoptosis of nucleus pulposus cells. Thus, Ad-hIGF-1 may be useful in the development of clinical interventions for disc degeneration.

\section{Introduction}

Intervertebral disc degeneration (IDD) is a common clinical diagnosis and is the leading cause of debilitating spinal disorders and resulting lower back pain (LBP) and physical disability (1). It is difficult to economically manage health problems such as LBP due to the escalating costs of healthcare services. Furthermore, it has a pronounced impact on society, given that it leads to decreased work efficiency among employees and disrupts the quality of life of patients (2-4). Aging is the greatest risk factor for developing IDD, as the incidence rate increases gradually with age (5). Due to the complexities of this disorder, the mechanisms of IDD are poorly understood. In this study, we hypothesized that the changes occurring in IDD are primarily manifested within cells and the extracellular matrix within the disc. The altered extracellular matrix composition of the disc directly defines the characteristics of IDD mechanics $(1,6)$. There are several possible causes of disc degeneration, including the decline of cell viability, modifications of extracellular matrix synthesis and distribution, as well as excessive cell loss due to apoptosis. Indeed, the extreme progression of apoptosis of nucleus pulposus cells can directly affect intervertebral disc (IVD) function (7).

Tumour necrosis factor (TNF)- $\alpha$ is a pro-inflammatory cytokine that plays a crucial role in disc degeneration. A number of studies have indicated that TNF is expressed in the normal IVD and that its expression increases with progressing age and disc degeneration. Therefore, TNF- $\alpha$ may be a key initiating factor in matrix degeneration. It may also act to upregulate interleukin (IL)-1 $\beta$ expression, which is known to play a major role in promoting pathological disc degradation (8-11). Previous studies have demonstrated that insulin-like growth factor (IGF)-1 stimulates the proliferation of human nucleus pulposus cells (12). The stimulation of bovine nucleus pulposus 
cells by IGF-1 and bone morphogenetic protein (BMP)-7 has a significant impact on anabolism through complementary and synergistic mechanisms on matrix formation. Compared to treatment with growth factor alone, the combination therapy of BMP-7 and IGF-1 may hold considerable promise in the treatment of IDD (13). If cells can overexpress IGF-1 alone, this may have considerable, positive impact on cell survival; however, to our knowledge, this has not been demonstrated to date.

Gene therapy is considered a potential therarpy for degenerative disc disease. In this study, our main objective was to determine the effects of the IGF-1 gene on the TNF- $\alpha$-induced apoptosis of rabbit nucleus pulposus cells and to investigate the potential anti-apoptotic mechanisms involved. To achieve these objectives, we constructed an adenoviral vector expressing the human IGF-1 (hIGF-1) gene and transfected nucleus pulposus cells with this vector. We used western blot analysis to assess transgene expression and terminal deoxynucleotidyl transferase (TdT)-mediated dUTP-biotin nick end-labeling (TUNEL) and flow cytometry (FCM) to quantify the apoptotic rate of nucleus pulposus cells.

\section{Materials and methods}

Cell culture. IVDs were obtained from lumbar spines of mature New Zealand white rabbits immediately post-mortem. From the IVDs, the nucleus pulposus was harvested, washed with Hanks' balanced salt solution (HBSS) and transported to our laboratory within $30 \mathrm{~min}$ of harvesting. The nucleus pulposus tissue was rinsed 3 times in HBSS and dissected into small fragments of $\sim 1 \mathrm{~mm}^{3}$ in size. The cells were isolated from the nucleus pulposus using sequential enzyme digestion. Subsequently, $0.25 \%$ trypsin was used for carrying out the initial $30-\mathrm{min}$ digestion followed by a wash with HBSS and incubation of the material in $0.1 \%$ collagenase type II at $37^{\circ} \mathrm{C}$ for $2-3 \mathrm{~h}$. The cells were collected by filtering the digested tissue through a $200-\mu \mathrm{m}$ mesh nylon cell strainer and centrifugation of the filtrate at $1,000 \mathrm{x}$ g for $5 \mathrm{~min}$. The cells were washed twice with phosphate-buffered saline (PBS) and then resuspended and grown in Dulbecco's modified Eagle's medium with Ham's F-12 nutrient mixture (DMEM-F12) supplemented with $10 \%$ (vol/vol) fetal bovine serum (FBS) plus $1 \%$ penicillin and streptomycin. The culture medium was changed every $2-3$ days. The phenotype of the nucleus pulposus cells was confirmed using positive immunostaining for type II collagen. Once the nucleus pulposus cells had formed a monolayer, they were allowed to expand exponentially until $\sim 80 \%$ confluence. Second-passage chondrocytes were used in all the experiments (Fig. 1A).

Construction and generation of recombinant adenoviral vector expressing $h I G F-1$ (Ad-hIGF-1). The adenoviral vector containing the hIGF-1 gene was constructed by Biowit Technologies Co., Ltd. (Shenzhen, China). Second-passage chondrocytes were digested using trypsin, transferred to 6-well plates and grown to a density of $1 \times 10^{5} / \mathrm{ml}$ in DMEM-F12 supplemented with $10 \%$ (vol/vol) FBS. After 24 h of adherence, the medium was changed to DMEM-F12 with $10 \%$ FBS containing TNF- $\alpha$ (100 ng/ml) with or without Ad-hIGF-1 for $48 \mathrm{~h}$ [the adenoviral titer was $4.0 \times 10^{9}$ plaque forming units $(\mathrm{PFU}) / \mathrm{ml}$. A subset of cells grown in DMEM-F12 with $10 \% \mathrm{FBS}$ for $48 \mathrm{~h}$ served as the controls.
$R T-P C R$. Total RNA was extracted from the nucleus pulposus cells using TRIzol reagent (Tiangen Biotech Co., Ltd., Beijing, China) according to the manufacturer's instructions. The primers for hIGF-1 (546 bp) were 5'-TGGCTTATCGAAATT AATACGACTC-3' (forward) and 5'-GGCTGATCAGCGGG TTTAAACTTAA-3' (reverse). The PCR procedure was as follows: denaturation at $94^{\circ} \mathrm{C}$ for $2 \mathrm{~min}$; 30 cycles of $94^{\circ} \mathrm{C}$ for $30 \mathrm{sec}, 55^{\circ} \mathrm{C}$ for $30 \mathrm{sec}$, and $72^{\circ} \mathrm{C}$ for $30 \mathrm{sec}$ followed by a $60^{\circ} \mathrm{C}$ elongation step for $10 \mathrm{~min}$. Electrophoresis of the RT-PCR products was performed using an agarose gel, and the results were analyzed by a gel imaging system.

Western blot analysis. Arter resolution by electrophoresis, proteins were separated by $10 \%$ sodium dodecyl sulfate (SDS)-polyacrylamide gel electrophoresis (PAGE). The proteins were transferred onto polyvinylidene difluoride (PVDF) membranes (Millipore, Bedford, MA, USA). The membranes were blocked with $5 \%$ non-fat dried milk in TBST $(10 \mathrm{mM}$ Tris-HCl, $150 \mathrm{mM} \mathrm{NaCl}$, and $0.05 \%$ Tween-20, $\mathrm{pH}$ 7.5) for $1 \mathrm{~h}$ at room temperature and then incubated with antibodies against hIGF-1 (1:200 dilution; Boster Biological Technology Ltd., Wuhan, Hubei, China) for $1 \mathrm{~h}$ at $37^{\circ} \mathrm{C}$. After washing twice with TBST buffer, the membranes were incubated with horseradish peroxidase-conjugated anti-mouse IgG secondary antibodies for $1 \mathrm{~h}$ at room temperature and detected using a Bio-Rad digital imaging system (Bio-Rad, Hercules, CA, USA).

TUNEL assay. Nucleus pulposus cells were collected and cultured in 6-well plates. Each well was covered with a 1x1-cm cover glass. The cover glasses were removed after $12 \mathrm{~h}$, and the cells adherent to the glass were fixed in $4 \%$ paraformaldehyde for $60 \mathrm{~min}$. Methanol containing $3 \% \mathrm{H}_{2} \mathrm{O}_{2}$ was applied for $5 \mathrm{~min}$ to inactivate endogenous peroxidase. The cells were then exposed to $0.1 \%$ Triton $\mathrm{X}-100$ at $4^{\circ} \mathrm{C}$ for $2 \mathrm{~min}$. These cells were subsequently incubated with $50 \mu \mathrm{l}$ of the TUNEL reaction mixture (5 $\mu$ l TdT-enzyme solution and $45 \mu$ l of nucleotide mixture solution) in the dark at $37^{\circ} \mathrm{C}$ for $60 \mathrm{~min}$. The cells were then exposed to 3,3'-diaminobenzidine (DAB) and then counterstained with hematoxylin. Finally, the cells were dehydrated using graded ethanol and covered with a xylene-based mounting medium. The percentage of TUNEL-positive cells from the control, TNF- $\alpha$ and TNF- $\alpha+$ Ad-hIGF-1 groups was quantified within 10 noncontinuous low-power fields (magnification, x100).

FCM. The cells were cultured in DMEM-F12 containing TNF- $\alpha(100 \mathrm{ng} / \mathrm{ml})$ with or without Ad-hIGF-1 for $48 \mathrm{~h}$. Cells cultured in DMEM-F12 with $1 \%$ FBS for $48 \mathrm{~h}$ served as the controls. The cells were digested using trypsin, then collected and washed in FCM buffer. The collected cells were re-suspended in FCM wash buffer. In order to detect cell apoptosis, the cells were incubated in the dark with $5 \mu \mathrm{l}$ of Annexin V-FITC incubation reagent for $15 \mathrm{~min}$ at $4^{\circ} \mathrm{C}$. This was followed by incubation with $10 \mu \mathrm{l}$ of propidium iodide (PI)-phycoerythrin (PE) for $5 \mathrm{~min}$ at $4^{\circ} \mathrm{C}$. The samples were analyzed within $30 \mathrm{~min}$ by FCM.

Statistical analysis. Data are presented as the means $\pm \mathrm{SD}(\mathrm{n}=3)$. Groups of data were compared statistically using the MannWhitney $\mathrm{U}$ test. Values of $\mathrm{P}<0.05$ were considered to indicate statistically significant differences. 


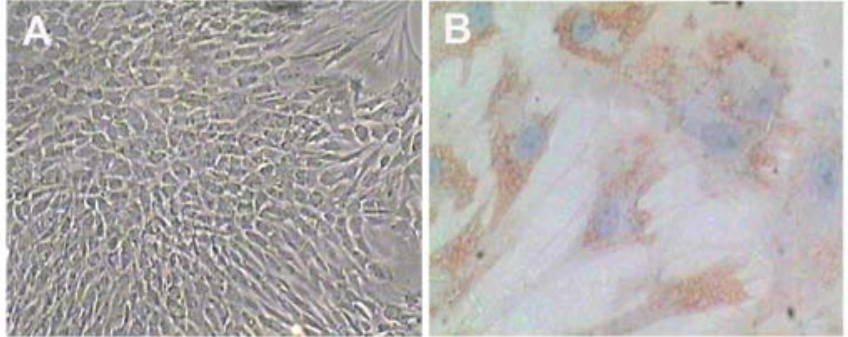

Figure 1. Expression of type II collagen in cultured nucleus pulposus cells (A) Cultured primary nucleus pulposus cells (x100). (B) Type II collagen (brown granules) expression in the cytoplasm of nucleus pulposus cells (x200).
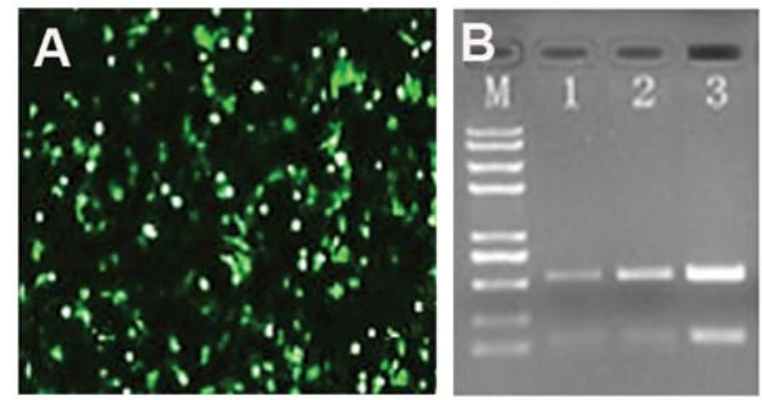

546 bp

Figure 2. Expression of hIGF-1 by HEK293 cells after transfection (A) Expression of hIGF-1 by HEK293 cells transfected with plasmid (Ad-GFP) (green). (B) Results from RT-PCR for IGF-1 gene in 293 cells transfected with various concentrations of adenovirus particles. Lane M, size markers; lane 1, Ad-hIGF-1 at 100-fold dilution; lane 2; Ad-hIGF-1 at 10-fold dilution; lane 3, without dilution.

\section{Results}

Isolation and culture of nucleus pulposus cells. Primary nucleus pulposus cells were obtained by sequential enzyme digestion and cultured in DMEM-F12 10\% FBS. To identify the phenotype of nucleus pulposus cells, immunostaining was used to detect type II collagen (Fig. 1B). The results revealed that these cells expressed type II collagen.

Generation of recombinant adenoviral vector Ad-hIGF-I expressing hIGF-1 exogenously. The adenoviral vector containing the hIGF-1 gene was successfully constructed by Biowit Technologies Co., Ltd. A built-in green fluorescent protein (GFP) contained in the Ad-hIGF-1 adenoviral vector was a unique feature of the Ad-hIGF-1 vector. As a result of GFP expression, we were able to effectively track the gene expression in the transfected cells. For the controls, we also constructed a recombinant adenoviral vector that only expressed GFP. HEK293 cells were transfected with the viral vector, Ad-GFP (Fig. 2). The viral transfection efficiency positively correlated with the viral titer (Fig. 2B). When the cells were $\sim 60$ to $70 \%$ confluent, transfection with Ad-hIGF-1 or the control vector, Ad-GFP, was performed. At $24 \mathrm{~h}$ posttransfection, fluorescence was the brightest, as observed under a fluorescence microscope; however, this fluorescence weakened after $48 \mathrm{~h}$ and disappeared after $72 \mathrm{~h}$ (Fig. 3). Western
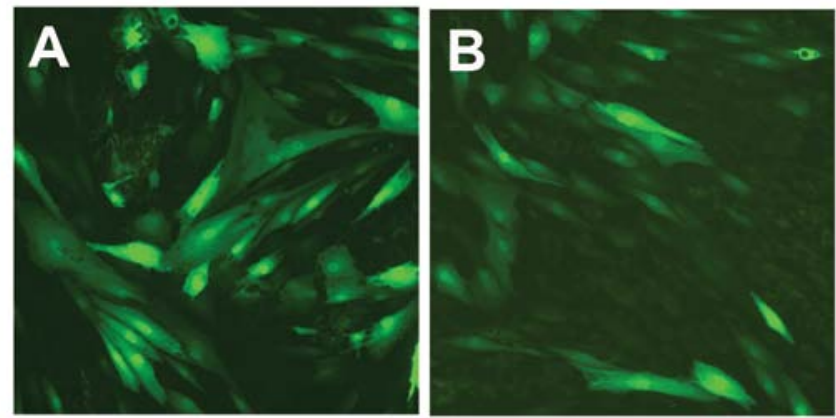

Figure 3. Expression of green fluorescent protein (GFP) in nucleus pulposus cells transfected by recombinant adenovirus AdIGF-1. (A) GFP expression $24 \mathrm{~h}$ after transfection (x100); (B) GFP expression $48 \mathrm{~h}$ after transfection (x100).

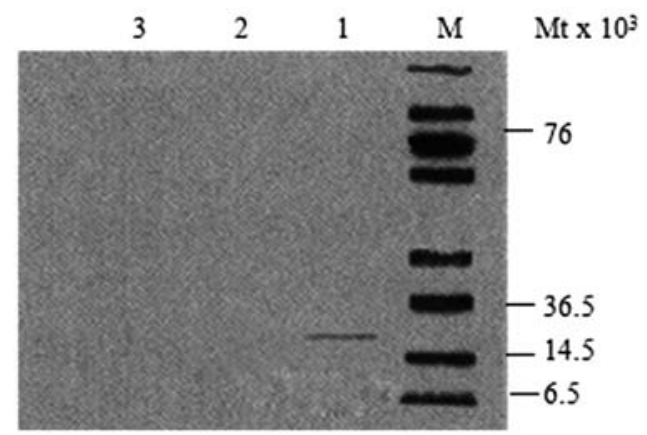

Figure 4. Detection of hIGF-1 protein expression by western blot analysis Lane M, protein marker; lane 1, Ad-hIGF-1 group; lane 2, tumour necrosis factor (TNF)- $\alpha$ group; lane 3, control group. In the TNF- $\alpha$ and control groups, there was no detectable hIGF-1 protein expression.

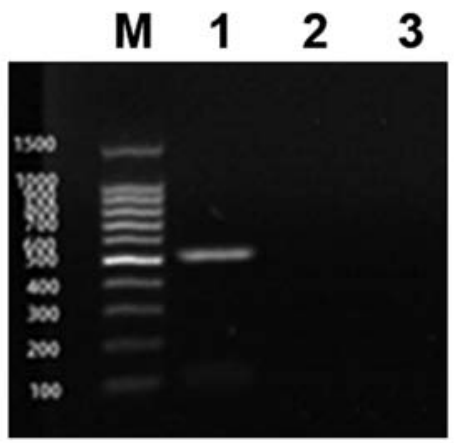

Figure 5. Detection of hIGF-1 mRNA expression by RT-PCR. Lane M, protein size marker; lane 1, Ad-hIGF-1 group; lane 2, tumour necrosis factor (TNF)- $\alpha$ group; lane 3, control group.

blot analysis revealed that IGF-1 in the nucleus pulposus was significantly expressed in the Ad-hIGF-1-transfected group, whereas no expression was reported in the TNF- $\alpha$-treated group or the control group (Fig. 4). The results of western blot analysis were confirmed by RT-PCR (Fig. 5).

TNF- $\alpha$ induces the apoptosis of nucleus pulposus cells. TUNEL staining revealed that the percentage of TUNELpositive cells was considerably greater in the TNF- $\alpha$-treated group compared with the controls (Fig. 6A-C). The results 

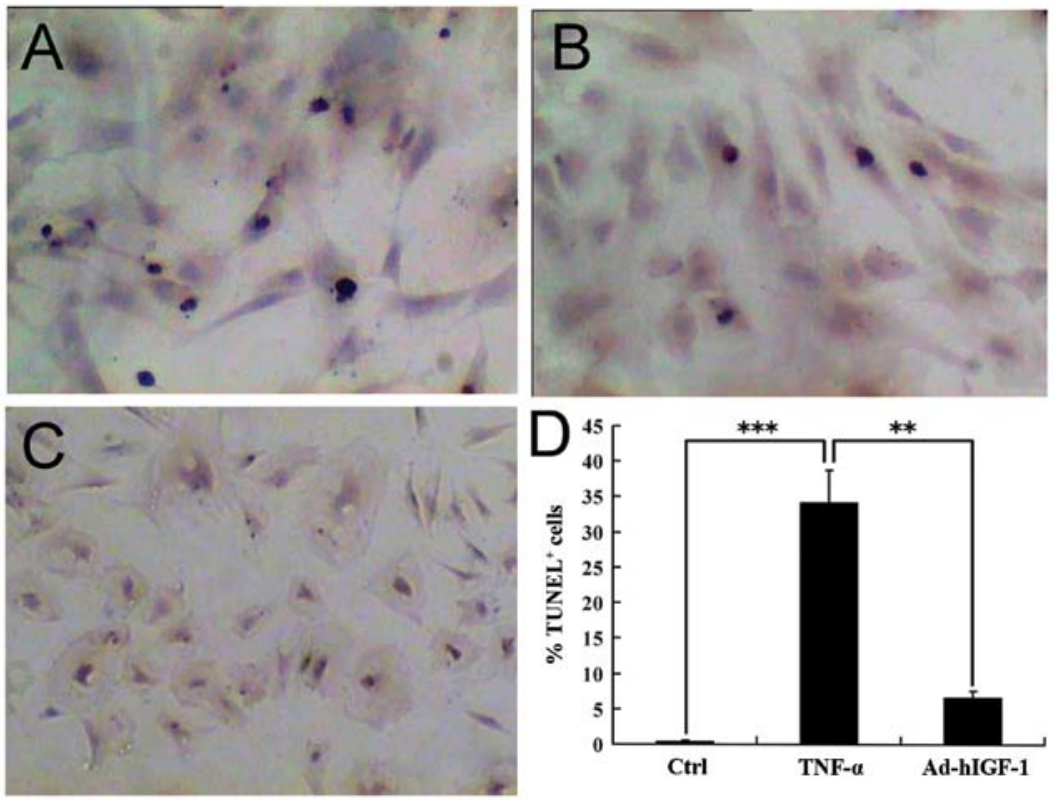

Figure 6. TdT-mediated dUTP-biotin nick end-labeling (TUNEL) indicates the inhibition of apoptosis of nucleus pulposus cells following transfection with Ad-hIGF-1. (A) Tumour necrosis factor (TNF)- $\alpha$ group of nucleus pulposus cells; (B) Ad-hIGF-1 group; (C) control group. Fewer TUNEL-labeled (apoptotitc cells) were observed following transfection with Ad-hIGF-1 (x100). (D) Quantitative analysis of nucleus pulposus cell apoptosis in the control, TNF- $\alpha$ and Ad-hIGF-1 groups. Ctrl, control. ${ }^{* *} \mathrm{P}<0.01,{ }^{* * *} \mathrm{P}<0.001$.


Figure 7. In vitro nucleus pulposus cell death as assessed by propidium iodide (PI) flow cytometry (FCM). Representative flow cytometric analysis for the distribution of dead (Annexin V/PI-stained) nucleus pulposus cells. (A) The control group showed no cell death overall. (B) The tumour necrosis factor (TNF)- $\alpha$ group exhibited increased cell death, as shown by FCM. (C) Ad-hIGF-1-transfected cells showed reduced Annexin V/PI labeling when compared to TNF- $\alpha$ treated cells. (D) Quantitative analysis of nucleus pulposus cells (TNF- $\alpha$ and Ad-hIGF-1 groups) undergoing early-stage apoptosis and the controls. Ctrl, control. ${ }^{* *} \mathrm{P}<0.01,{ }^{* * * * *} \mathrm{P}<0.001$.

from TUNEL assay were confirmed by FCM (Fig. 7A-C). IGF-1 suppressed the TNF- $\alpha$-induced apoptosis of nucleus pulposus cells. TUNEL analysis indicated that the TNF- $\alpha$ induced apoptosis was significantly suppressed $(\mathrm{P}<0.01)$ in the Ad-hIGF-1 group (Fig. 6A and B). This suggests that hIGF-1 inhibited the TNF- $\alpha$-induced apoptosis of nucleus pulposus cells. The results of FCM revealed that the percentage of nucleus pulposus cells exhibiting signs of early stages of apoptosis was significantly higher in the TNF- $\alpha$ group compared with the controls $(\mathrm{P}<0.01)$ (Fig. 7A-C), but was significantly lower in the Ad-hIGF-1-treated group compared with the TNF- $\alpha$-treated group $(\mathrm{P}<0.01)$ (Fig. 7A and $\mathrm{B})$. 


\section{Discussion}

Over the years, a number of studies have focused on elucidating the role of cytokines in the pathogenesis of IDD. IL-1 $\beta$ and TNF- $\alpha$ are considered principal pro-inflammatory cytokines. TNF- $\alpha$ is closely associated with IDD, as it suppresses matrix gene expression, but also regulates cell-cell and cell-matrix communication and cell growth in the invertebral disc (14). It has been demonstrated that TNF- $\alpha$ inhibits the expression of prostaglandins and type II collagen by increasing the expression of matrix metalloproteinases (MMPs) and a disintegrin and metalloproteinase with thrombospondin motifs (ADAMTS)-4 which are among the major factors in IVD degeneration (14). Late-stage disc degeneration is characterized by a reduction in the number of nucleus pulposis cells and both IL- $1 \beta$ and TNF- $\alpha$ can induce nucleus pulposus cell apoptosis $(9,15)$. Therefore, we hypothesized that IL-1 $\beta$ and TNF- $\alpha$ can significantly contribute to this loss. In addition, TNF- $\alpha$ can upregulate IL- $1 \beta$ expression and may be an important initiating factor in matrix degeneration (10).

IGF-1 effectively stimulates the proliferation of human nucleus pulposus cells (16). As recently demonstrated, IGF-1 stimulates the proliferation of human IVD cells through the MEK/ERK and PI-3K/Akt pathways $(12,18)$. Studies have proven the importance of gene therapy in the treatment of disc degeneration, and adenoviral vectors are considered an effective and reliable method for delivering exogenous genes to the IVD (19-21).

In this study, nucleus pulposus cells were successfully transfected with Ad-hIGF-1, and based on the results of RT-PCR and western blot analysis, we deduced that the transfected cells effectively expressed hIGF-1. The results from TUNEL assay and FCM indicated that the rate of apoptosis was particularly high in the nucleus pulposus cells treated with TNF- $\alpha$ compared with the controls. Ad-hIGF-1 significantly reduced apoptosis induced by $\mathrm{TNF}-\alpha$, suggesting that hIGF-1 reversed the TNF- $\alpha$-mediated apoptosis of nucleus pulposus cells in vitro. The results from FCM also suggested that TNF- $\alpha$ induced both the early- and late-stage apoptosis of nucleus pulposus cells. Moreover, apoptosis was suppressed by hIGF-1. Taken together, these results indicate that Ad-hIGF-1 may contribute to the development of clinical interventions for disc degeneration. In the IVD, the relatively encapsulated and avascular environment of the nucleus pulposus may prohibit elevated immune response and support the prolonged and enhanced expression of the IGF-1 gene.

In conclusion, the findings of this study illustrate that the adenoviral vector, Ad-hIGF-1, can successfully infect nucleus pulposus cells in vitro and can effectively enhance the expression of IGF-1. IGF-1 can reverse the TNF- $\alpha$-induced apoptosis of nucleus pulposus cells. Due to such beneficial effects, transfection with Ad-hIGF-1 may be a prospective therapeutic strategy and may aid the development of novel clinical interventions for disc degeneration.

\section{Acknowledgements}

This study was supported by the Key Research Foundation of Education Bureau of Anhui Province, China (KJ2011A204).

\section{References}

1. Freemont AJ: The cellular pathobiology of the degenerate intervertebral disc and discogenic back pain. Rheumatology (Oxford) 48: 5-10, 2009.

2. Becker A, Held H, Redaelli M, et al: Low back pain in primary care: costs of care and prediction of future health care utilization. Spine (Phila Pa 1976) 35: 1714-1720, 2010.

3. Dagenais S, Caro J and Haldeman S: A systematic review of low back pain cost of illness studies in the United States and internationally. Spine J 8: 8-20, 2008.

4. Asche CV, Kirkness CS, McAdam-Marx C and Fritz JM: The societal costs of low back pain: data published between 2001 and 2007. J Pain Palliat Care Pharmacother 21: 25-33, 2007.

5. Nasto LA, Wang D, Robinson AR, et al: Genotoxic stress accelerates age-associated degenerative changes in intervertebral discs. Mech Ageing Dev 134: 35-42, 2013.

6. Smith LJ, Nerurkar NL, Choi KS, et al: Degeneration and regeneration of the intervertebral disc: lessons from development. Dis Model Mech 4: 31-41, 2011.

7. Kim KW, Kim YS, Ha KY, et al: An autocrine or paracrine Fas-mediated counterattack: a potential mechanism for apoptosis of notochordal cells in intact rat nucleus pulposus. Spine (Phila Pa 1976) 30: 1247-1251, 2005.

8. Bachmeier BE, Nerlich AG, Weiler C, et al: Analysis of tissue distribution of TNF-alpha, TNF-alpha-receptors, and the activating TNF-alpha-converting enzyme suggests activation of the TNF-alpha system in the aging intervertebral disc. Ann NY Acad Sci 1096: 44-54, 2007.

9. Zhang CC, Zhou JS, Hu JG, et al: Effects of IGF-1 on IL-1 $\beta$-induced apoptosis in rabbit nucleus pulposus cells in vitro. Mol Med Rep 7: 441-444, 2013.

10. Millward-Sadler SJ, Costello PW and Freemont AJ: Regulation of catabolic gene expression in normal and degenerate human intervertebral disc cells: implications for the pathogenesis of intervertebral disc degeneration. Arthritis Res Ther 11: R65, 2009.

11. Weiler C, Nerlich AG, Bachmeier BE and Boos N: Expression and distribution of tumor necrosis factor alpha in human lumbar intervertebral discs: a study in surgical specimen and autopsy controls. Spine (Phila Pa 1976 ) 30: 44-53, 2005.

12. Pratsinis $\mathrm{H}$, Constantinou V, Pavlakis K, et al: Exogenous and autocrine growth factors stimulate human intervertebral disc cell proliferation via the ERK and Akt pathways. J Orthop Res 30: 958-964, 2012.

13. Kim JS, Ellman MB, An HS, et al: Insulin-like growth factor 1 synergizes with bone morphogenetic protein 7-mediated anabolism in bovine intervertebral disc cells. Arthritis Rheum 62: 3706-3715, 2010.

14. Séguin CA, Pilliar RM, Roughley PJ and Kandel RA: Tumor necrosis factor-alpha modulates matrix production and catabolism in nucleus pulposus tissue. Spine (Phila Pa 1976 ) 30: 1940-1948, 2005.

15. Wei A, Brisby H, Chung SA and Diwan AD: Bone morphogenetic protein-7 protects human intervertebral disc cells in vitro from apoptosis. Spine J 8: 466-474, 2008.

16. Zhang R, Ruan D, Zhang C. Effects of TGF-beta1 and IGF-1 on proliferation of human nucleus pulposus cells in medium with different serum concentrations. J Orthop Surg Res 1: 9, 2006.

17. Mavrogonatou E and Kletsas D: Effect of varying osmotic conditions on the response of bovine nucleus pulposus cells to growth factors and the activation of the ERK and Akt pathways. J Orthop Res 28:1276-1282, 2010.

18. Zhang M, Zhou Q, Liang QQ, et al: IGF-1 regulation of type II collagen and MMP-13 expression in rat endplate chondrocytes via distinct signaling pathways. Osteoarthritis Cartilage 17: 100-106, 2009.

19. Paul R, Haydon RC, Cheng H, et al: Potential use of Sox9 gene therapy for intervertebral degenerative disc disease. Spine (Phila Pa 1976) 28: 755-763, 2003.

20. Moon SH, Nishida K, Gilbertson LG, et al: Biologic response of human intervertebral disc cells to gene therapy cocktail. Spine (Phila Pa 1976) 33: 1850-1855, 2008.

21. Cao D, Quan Z, Jiang D, et al: Effect of adenovirus human bone morphogenetic protein 4 on human degenerative lumbar intervertebral disc cells. Zhongguo Xiu Fu Chong Jian Wai Ke Za Zhi 6: 1442-1447, 2012 (In Chinese). 